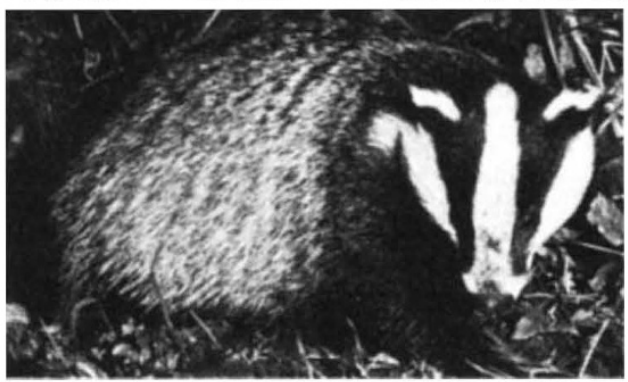

\title{
The Great Badger Debate
}

What follows is a brief summary of the report Badgers, Cattle and Tuberculosis, published by the British Ministry of Agriculture, Fisheries and Food last Octoher and a comment by its author, Lord Zuckerman, on various criticisms that have been raised, some of them in Nature

\section{Report and implications}

Bovine tuberculosis has been recognized as a serious problem in the United Kingdom (and also a source of human tuberculous infection) at least since 1913, when steps were first taken to control the disease. Farmers were encouraged to register herds free from tuberculosis by means of a premium price for the milk they produced, and infected cattle were also slaughtered compulsorily. But bovine infection continued, with unexplained "breakdowns" even in attested herds.

The link between bovine tuberculosis and badgers was first recognized in 1971, with the discovery of tuberculous lesions in a badger found dead. The organism responsible was found to be Mycobacterium bovis, that responsible for bovine tuberculosis. It now appears to be common ground that badgers can be infected by this organism. In 1975, ministry of ficials began controlling badgers found within a specified radius of infected

\section{Zuckerman's case}

The 6 November 1980 issue of Nature (p.6) carried a brief account of a report on tuberculosis (TB) in badgers and cattle which I had prepared for the Minister of Agriculture, Fisheries and Food. The report was written in response to a request for an assessment of the soundness or otherwise of the scientific evidence on which the ministry based the view that badgers in parts of the South West of England constitute a reservoir of the bovine tubercle bacillus. Because of its statutory responsibility to suppress TB in cattle, I was also asked whether the government was justified in its policy of destroying badgers where there was presumptive evidence of the presence of tuberculous badgers that might be responsible for outbreaks of TB in neighbouring cattle.

During my investigation I had consulted several scientists engaged in the study of animal disease, as well as practising veterinary surgeons. All agreed with the findings of the ministry's scientific and veterinary officers with many of whom $I$ had conferred. My own review of the evidence left me satisfied that badgers in certain areas of the South West are heavily infected with the bovine tubercle bacillus, and sometimes transmit the diseasc to cattle grazing on pasture that has been contaminated with their sputum, pus, urine and faeces. I uncovered not a vestige of scientific foundation for widely publicized statements from "protestors" to the effect that none of the story was herds of cattle by the use of cyanide gas. These procedures were abandoned in October 1979, but have been resumed in South West England since the publication of the Zuckerman report.

The transmission of tuberculosis from badgers to cattle is accepted in the report, which says that viable $M$. bovis have been recovered from grass sprayed with the urine of infected badgers (but more easily in the winter than the summer). The report also says that during the period in which control by gassing was carried out, " 185 out of 2,432 badgers that had been collected in the vicinity of 477 farms where breakdowns had occurred" turned out to be infected with $M$. bovis. The report also records how, in New Zealand, the opossum was discovered to be a reservoir of bovine tuberculosis, and gives (in its Appendix 11I) accounts of how, at several farms in South West England, infection in badgers has been linked with breakdown among herds of cattle.

The South West of England sustains a third of the United Kingdom's cattle, and also dense populations of badgers. It is common ground between Lord Zuckerman and those who have criticized his report that badgers are also prevalent in parts of England, where bovine tuberculosis is rare. Lord Zuckerman concludes, in his report, that the population density of badgers determines both their susceptibility to infection and the risk of transmission to cattle. The frequency of infection among badgers in the South West of England has been found to be as great as one in five in some places.

Among the recommendations in the report were the resumption of badger control by gassing in the South West, the investigation of the incidence of tuberculosis among badgers in contiguous parts of the country, financial support for field studies of the British badger population, the publication of annual reports of the progress of the control campaign and a more thorough review of what will by then have been learned of the badger problem after an interval of three years.

"true" and that, in effect, the whole thing was a hoax perpetrated by government servants.

It was, of course, unlikely that a fresh display of the facts would necessarily succeed in "converting" the opposition. But it came as a surprise to read first, in an unsigned article in New Scientist (4 December 1980, p.619), and then in a letter published in Nature intended as a corporate statement by The Mammal Society (11 December 1980, p.532), that the conclusions of my report, in which I had assembled not only more, but also more up-to-date, information on the subject than had been made available before, were questionable on scientific grounds. Apart from agreeing that "the badger is a major reservoir of bovine TB in certain limited areas of South West England, and hence a potential danger to the cattle in those areas", the society asserts that my report gave a "biased interpretation of the evidence", that "many of (my) conclusions were not justified" by the data which I had presented, and that "factually misleading statements" therefore needed to be corrected.

\section{The report}

My main conclusions, set out in the report, were first, that "by any rational cpidemiological standards, badgers (in some parts of South West England) now constitute a significant reservoir of the bovine strain of the tubercle bacillus"'. The Mammal Society thinks otherwise. It declares that "there is no scientific evidence to justify" the view that badgers in the affected areas constitute "a highly infected population'. If the society is sufficiently well informed to make this extraordinary claim, the onus of providing proof, as Dr Plowright has already pointed out (Nature 1/8 January 1981, p.8), is on them.

Next, the Mammal Society was, to say the least, irresponsible in their quotation of what was in the report. I did not "overlook" the fact that during the first seven months of the moratorium the percentage of badgers with TB had fallen slightly in Cornwall at the same time as it had increased in Gloucestershire and Avon; this is precisely what my figures revealed. Nor did I interpret these or any of the other available figures in the "black or white" way that the Mammal Society suggests I did and, now in reverse, that it itself does. The interpretations I provided were the best that could be put on the figures, and were carefully qualified. Conclusions contrary to those I drew from the facts would have been absurd.

The Mammal Society is not criticizing when it merely repeats what I emphasized: namely, that the disease in badgers occurs only in "pockets". But it is falsifying what I did write when it says that I had asserted that badgers in the affected areas of the South West are spreading TB to badgers in other areas. What I wrote was that no one knows how one pocket of infection in badgers relates to another (paragraph 134 of the report). And I did not say that TB is (my italics) a major hazard to the survival 
of the badger (even if it clearly is to the badgers in the areas already affected). What I said was, were the disease "to take hold in badgers in other parts of the country" "there is no saying what the consequences would be ... as they relate to the survival of the badger".

In considering the persistence or extinction of a disease in a given locality, the statistical laws governing its spread must be borne in mind. If the average number, $x$, of new infections from a unit which becomes infected is less than 1, the disease will die out. If greater than 1 , the disease, once established, will spread. However, if $x$ is not markedly greater than 1 , there is still a good chance that a single infection will not result in its establishment; but if repeated new infections occur, then eventually one of them will be successful in establishing the disease.

With badgers two separate units are involved: first, the individual within a badger sett, and second, the setts themselves. As Dr Plowright has re-emphasized, the epidemiological conditions are highly favourable for transmission of TB within a sett. Transmission between setts seems to depend very greatly on such factors as density of population, contiguity of setts, and fighting between members of different setts. In an area which adjoins another where the disease is endemic, there will be a continuous flow of infection from the infected area to the border setts of the other area. But if $x$ for the second area is less than 1 , the infection will not spread through the whole area.

\section{Infectivity}

It is obvious that the period during which a unit remains infective depends on the nature of the disease. For a disease which kills quickly or in which there is complete recovery without the unit becoming a carrier, the period will be short. In a disease such as TB it will be considerably longer. Note also that the value of $x$ will change with time, both because of the direct effect of the disease on population density and of acquired immunity, and also because of other unrelated factors.

I have discussed these matters with $\mathrm{Dr}$ Frank Yates of Rothamsted. In his view, my supposition that bovine TB may have been prevalent in badgers throughout the country before its virtual eradication from cattle is almost certainly justified (paragraph 133 of my report). After its eradication from cattle and the consequent absence of cross-infection the disease died out in areas of the country in which $x$ was less than 1 , as it seems to have done in most of the UK.

Dr Yates has also pointed out that once the disease has died out in an area, this area will remain free as long as no new infection is introduced, but if owing to an increase in the density of population or for other reasons $x$ becomes greater than 1 , the disease, once established, will then spread until the whole area is infected. The question put by the Mammal Society as to why areas in other parts of the United Kingdom with a badger population density which is presumed to be as great as in the South West were not infected, seems basically simple. Either $x$ has remained less than 1, or they have just been lucky.

Before turning to certain further information about the prevalence of $\mathrm{TB}$ in badgers that has become available since my report was written, it is necessary to refer to what I said about the incidence of breakdowns in cattle, since this is also something about which the Mammal Society is critical.

The campaign to suppress bovine TB resulted in a decline in the incidence of reactors in cattle herds, not only in the South West, but also in the rest of England. This the Mammal Society acknowledges. But, as Dr Plowright has already pointed out the society failed to note in its statement the critical fact that while the incidence of herd breakdowns has fallen dramatically in all parts of the country once the culling of tuberculous cattle was made compulsory in 1950, in the affected areas of the South West it has consistently remained more than five times the national average. This difference was the essential reason for the search for a "cause", and for the resultant finding of a reservoir of the bovine tubercle bacillus in badgers in the affected areas. And here is where the Mammal Society's criticisms have gone wildly astray. Their suggestion that one possible interpretation of the figures given in the Report was that unknown "subtle factors" resulted in a decline of TB in both cattle and badgers throughout the country, and that gassing had little significant effect on the overall timing or rate of decline is, as Dr Yates has shown (Nature 22 January 1981, p.218), based on a very superficial and distorted use of the evidence. His more detached presentation clearly indicates that the gassing campaign appears to have had a considerable effect in reducing the very high incidence of herd breakdowns in the worst affected parts of the South West. What the Mammal Society did was lump together in a graph my figures for TB in badgers in all the affected counties of the South West, whereas as Dr Yates has shown, there is a radical difference when one compares the parallelism in the prevalence of TB in badgers and the incidence of breakdown in cattle as between Cornwall and Gloucestershire on the one hand, and Devon, Dorset, Somerset and the rest of England on the other.

In its haste to criticize, the Mammal Society has also clearly failed to realize that the data assembled in my report were the best available at the time, and that more would be published as they became available - I have recommended annual reviews. The society's charge that it was "manifestly untrue" that herd breakdowns reflected a high local prevalance of TB in badgers was based on the

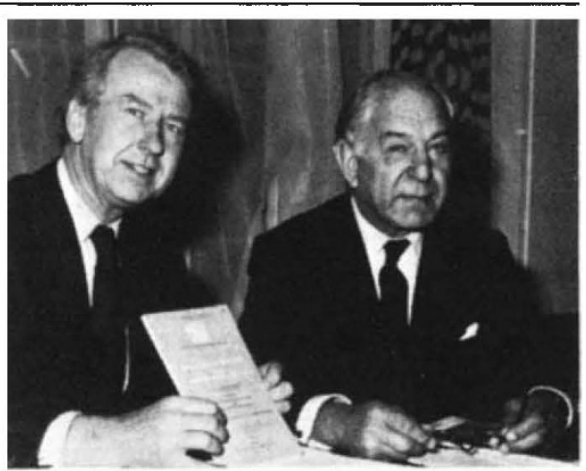

Lord Zuckerman (right) with Agriculture Minister Peter Walker and the report

figures for Cornwall, where only 15 per cent $(51 / 340)$ of the breakdowns were attributed to badgers. What the society failed to bring to the attention of its readers - their examination of the evidence must indeed have been cursory if they themselves failed to notice it - is that, as Dr Yates did note, in Cornwall 69 per cent $(234 / 340)$ of the breakdowns were classed as unknown, whereas in the rest of the South West (plus Sussex) only 26 per cent $(107 / 417)$ were so classed, 67 per cent $(280 / 417)$ being attributed to badgers.

\section{Figures}

Before rushing into print the society might indeed have enquired further about the Cornish figures. I have now obtained a breakdown by years which gives:

\begin{tabular}{lcc} 
Cornwall & Unknown & Badgers \\
$1972-73$ & 110 & - \\
$1974-75$ & 88 & 10 \\
$1976-78$ & 36 & 41 \\
\cline { 2 - 3 } & 234 & 51 \\
\hline
\end{tabular}

The explanation is simple. Badger investigations were only begun in Cornwall as a routine measure in 1974 . The progressive reduction in the proportion of "unknowns" indicates their increasing thoroughness. I am also informed that for the whole of Cornwall 72 per cent of the 51 outbreaks attributed to badgers were within 2 miles of setts containing infected badgers, and 33 per cent were within half a mile. For the West Penwith area the corresponding percentages were 97 and 47 .

The data which I had when I wrote my report related to only the first seven months of the period of the moratorium (Table 18 of my report). I have now been provided with figures for the first twelve months during which no new gassing operations were carried out. During the year, 611 badgers were autopsied in connection with official investigations to determine the source of herd breakdowns in the affected areas of the South West, and 73 (12 per cent)were found to be infected. Needless to say, there were differences between the counties concerned, but since the significance of these differences could only be determined through a detailed analysis aimed at revealing their relation to specific 
herd breakdowns, they hardly merit discussion.

More important is the information that is now available about the herd breakdowns that occurred in the affected areas in the first twelve months of the ban, about which nothing positive could be said on the basis of the data that were made available to me when I drew up my report, and in which reactors were found in only 0.7 per cent of the 17,411 herds that were tested. Between April and September a further 6,845 herds have been examined, bringing the total up to 24,256 . The percentage of reactor herds had risen substantially in comparison with the first seven months of the moratorium in every one of the affected counties of the South West. Overall, the percentage for the period April to September was 2.2 , double that for the period January to September 1979 . For the year of the moratorium as a whole it was some ten times higher than for the rest of England.

The anonymous article in New Scientist (4 December 1980) referred not only to the Mammal Society's statement, but also (1) to certain critical comments by Dr Hans Kruuk that follow the same line as the society's statement; and (2) to an assertion by Miss Eunice Overend, described as an "enthusiast" of badgers, about the speed with which TB develops in badgers; she is quoted as saying that while TB may develop quickly in captive badgers, "it wouldn't happen in the wild', In answer to an enquiry I put to her, she also challenges the views of veterinarians about the speed with which the disease can take hold in cattle.

I have no doubts about Miss Overend's sincerity, but her "facts" happen to be wrong. Advanced TB lesions have been found in the lungs of wild badger cubs ranging in age from four to nine months, which had clearly been infected by routes other than bite wounds, and it is estimated that at least some of these cubs would have succumbed to the disease in a matter of weeks.

\section{Anomalies}

Of course, there are still many "anomalies" in the story, which further enquiry might elucidate. But every one of the so-called anomalies referred to in the Mammal Society's manifesto, all its speculative questions, "why this, why not that", are, as Dr Plowright has pointed out, mentioned in my report. Setting them out as a form of criticism adds nothing to the story. I hope that the further enquiries which I suggested should be undertaken to clear up a number of "unknowns", and which the Minister of Agriculture, Fisheries and Food, in his statement to Parliament said would be started as soon as the necessary arrangements can be made, will be entrusted to experienced and competent hands.

So much for the "scientific" criticisms that have been levelled at my report. No new facts have been brought forward. Nothing that has been said would make it anything but irresponsible for the government to devise a policy of action for the suppression of bovine TB, to which it is statutorily committed, other than what it is doing. Unfortunately, the Mammal Society's statement has been used as part authority for a press-release by the UK branch of the World Wildlife Fund, in which the government's acceptance of my report is in effect condemed. This was issued without any consultation with the Animal Health division of the Ministry of Agriculture, Fisheries and Food (MAFF).

As a scientist I have been a dedicated supporter of the conservation movement since before the Second World War, and as a scientific adviser to government I played a part in organizing our own formal institutions for the protection of the environment. I therefore find it regrettable that the only way I could have found favour with those who are concerned to obstruct the government's anti-bovine TB policy would have been either to suppress, or to fudge, the evidence which had been gathered by those scientists primarily concerned over many years with the problem of TB, not only in cattle, but also in badgers (as well as in those luckier representatives of the wild fauna of the country which, by comparison, are relatively resistant to the infection).

\section{Mammal Society}

The Mammal Society was one of the bodies which submitted written evidence to help my enquiry, citing Stephen Harris and Dr Kruuk as its two authorities since, so the Society said, they were "the two principal non-MAFF scientific researchers on badgers in this country'. Presumably both helped in the drafting of the corporate statement which was designed to correct my "factually misleading statements". Since there can be few land-mammals that have generated as much proprietary interest as has the badger among the handful of naturalists who have added to our knowledge of the ways of the animal, I should note that I cannot find in the zoological literature any paper by Harris on badgers. Dr Kruuk's present studies relate to the animal's natural history, and I referred (paragraph 141 of my report) to a proposal which he had already published, that "pastures in infected areas should be so dressed as to reduce drastically the population of earthworms which they sustain", commenting, however, that I did not know "whether there is a way of doing this without detriment to the cattle which also forage the pastures that would be treated", nor "what those concerned with the welfare of birds - which also eat worms - would think about the measure which Dr Kruuk has proposed" Before turning to the badger, Dr Kruuk studied the behaviour and ecology of gulls and carnivores - mainly hyenas. For this work he was awarded the Zoological Society's

\section{Scientific Medal in 1975.}

The errors in the Mammal Society's statement suggest that its badger panel did not include experienced epidemiologists or veterinary scientists. That it should have done is clear. For contrary to what has been said to me by the society's president, $\mathrm{Dr}$ Ernest Neal, the study of mammals is not just "a rather narrow field of interest" that can be covered by watching the behaviour of animals in the wild. Whether or not it was intended, the misleading impression which the statement has made on the media, and on those who now clamour against the government's decision, was that the Mammal Society is a body that can make pronouncements on animal disease which, if anything, might have been expected from the Royal College of Veterinary Surgeons, or from a commitee set up ad hoc by the Royal Society.

Of course members of the Mammal Society are free if they so wish to criticize the scientific validity of the data that I collected and to question my interpretations, but by insisting that it has the right to make a corporate, but anonymous, statement of the kind it has the young Mammal Society has, in my view, done itself harm. Here it is useful to refer to the main editorial in Nature of 11 December 1980 (p.525) entitled "Code of conduct for national academies", which pointed out that even "The Royal Society has no means by which it can reach a corporate opinion on any substantial issue of public policy ... for example, say, government policy on nuclear power stations or whether manufacturers of drugs should in future be liable for side effects". Of course, the Royal Society could set up committees to look into such matters, but then its members would be named, and those Fellows of the Society not on the committees would certainly not be committed to whatever recommendations were put forward. If it wishes its published statement to be considered further then the Mammal Society should clearly name the "experts" who were responsible for its drafting. Dr Yates suggests that what the Mammal Society has done illustrates "the way in which distorted and partial graphic presentation can be used for propaganda purposes". It might have been more charitable to say that what was done was done out of ignorance. But then, as Gunnar Myrdal has put it, one has to remember that ignorance, like knowledge, can be steered for a purpose.

Not only was there no scientific value in the Mammal Society's statement; it was clearly the work of only a handful of its members, none of whom, so far as anyone can tell, had ever worked on the epidemiology of tuberculosis in animals. It is unfortunate that the society's action should have encouraged those who protest against MAFF's findings and policies in the belief that they have scientific support for the new wave of opposition which they have already mounted. 